\title{
Macro-Fouling Faunal Assemblage in Hambantota Port
}

\author{
Jayasundara R.M. and Ranatunga R.R.M.K.P.*
}

\author{
Department of Zoology, University of Sri Jayewardenepura, Sri Lanka \\ *kamal.ranatunga@gmail.com
}

\begin{abstract}
Invasive species recognized as one of the greatest threats to global biodiversity and biofouling on submerged structures within a port environments is one of the major pathways of invasions by Non Indigenous Species (NIS). Early detection and monitoring of such deleterious organisms is crucial, since control is nearly impossible once established. The present work is a baseline study for biofouling faunal assemblage in Hambantota Port. The study consisted of two stages; initial sampling for investigating existing biofouling assemblage and review sampling after 10 months in order to monitor the changes in community structure. Sampling followed an international protocol developed by Center for Research on Introduced Marine Pest (CRIMP).

Samples were scraped from submerged hard substrata in 12 sampling sites with the assistance from divers. Organisms in scraped samples were identified to the nearest taxonomic level using taxonomic guides and databases. All together 90 species were recorded during the study. Among them, 72 species were recorded within the baseline sampling and additional 18 during review sampling. Highest number of species recorded from phylum Mollusca (54) followed by Arthropoda (11), Annelida (11), Chordata (5), Cnidaria (4),Echinodermata (3) and Bryozoa (2). Balanus amphitrite, Balanus tintinnabulum, were the most common species in baseline sampling while Chthamalus sp.1 and Cellana radiata in the review sampling. Balanus tintinnabulum, Clypidina notata, Cellana radiata, Thais echinata, Harmoniconus parvatus and Saccostrea cucullata were the common species found in both sampling.
\end{abstract}

In baseline sampling, highest number of species was recorded from Oil Pier (31) while least number (1) was recorded in the outer harbour artificial island. In review sampling, highest species richness (12) recorded in west bank while least species richness (5) was recorded within the West Breakwater. The most noteworthy finding is that eight globally known invasive species which include, Rapana venosa, Phallusia nigra, Perna perna, Brachidontes pharaonis, Balanus amphitrite, Balanus reticulates, Balanus trigonus and Schizoporella errata were recorded. Among them Rapana venosa was recorded only in review sampling and rest in baseline sampling.

Keywords: Biofouling, Non-indigenous species, Baseline study, Hambantota Port

Proceedings of the International Forestry and Environment Symposium 2016, Department of Forestry and Environmental Science, University of Sri Jayewardenepura, Sri Lanka. 